\title{
An Affect Theory of Social Exchange ${ }^{1}$
}

\author{
Edward J. Lawler \\ Cornell University
}

\begin{abstract}
This article develops a theory that explains how and when emotions, produced by social exchange, generate stronger or weaker ties to relations, groups, or networks. It is argued that social exchange produces positive or negative global feelings, which are internally rewarding or punishing. The theory indicates that social units (relations, groups, networks) are perceived as a source of these feelings, contingent on the degree of jointness in the exchange task. The jointness of the task is greatest if (1) actors find it difficult to distinguish their individual effects on or contributions to solving the exchange task (nonseparability) and (2) actors perceive a shared responsibility for success or failure at the exchange task. The theory explicates the effects of different exchange structures on these conditions and, in turn, on cohesion and solidarity. Implications are developed for network-to-group transformations.
\end{abstract}

This article proposes an affect theory of social exchange. The purpose is to incorporate emotions as an explicit, central feature of social exchange processes. The article accomplishes this by (1) conceptualizing individual actors as emoting as well as cognizing, feeling as well as thinking, (2) treating emotions as internal reinforcements or punishments, and (3) analyzing how individuals' relational and group attachments are connected to their emotional experiences in social exchange. The theory moves beyond the traditional Skinnerian foundation (Homans 1961; Emerson 1972a) of exchange theory, as well as its more recent rational choice var-

\footnotetext{
${ }^{1}$ This article was conceived while I was a fellow at the Center for Advanced Study of the Behavioral Sciences in 1996-97. I gratefully acknowledge the financial support provided by National Science Foundation during that year (grant no. SBR-9022192). The empirical work that stimulated many of these ideas was also supported by the NSF (SES 9222668 and SBR 9614860). Shane Thye, Lisa Troyer, and Jeongkoo Yoon provided valuable comments on an earlier version. The article also benefited from comments of members of the Iowa Theory Workshop. Direct correspondence to Edward J. Lawler, School of Industrial and Labor Relations, Cornell University, Ithaca, New York 14853. E-mail: ej13@cornell.edu
}

(C) 2001 by The University of Chicago. All rights reserved. 0002-9602/2001/10702-0002\$10.00 
American Journal of Sociology

iants (Cook and Whitmeyer 1992). It argues that emotions produced by exchange structures and processes are critical to an understanding of how and when social exchanges promote or inhibit solidarity in relations or groups.

Social exchange is conceptualized as a joint activity of two or more actors in which each actor has something the other values. The implicit or explicit task in exchange is to generate benefit for each individual by exchanging behaviors or goods that actors cannot achieve alone (Thibaut and Kelley 1959; Homans 1961; Emerson 1972b). The affect theory of social exchange expands the domain of exchange theorizing in two main ways. First, exchange outcomes-rewards and punishments-are construed as having emotional effects that vary in form and intensity. When exchanges occur successfully, actors experience an emotional uplift (a "high"), and when exchanges do not occur successfully, they experience emotional "downs" (Lawler and Yoon 1996). Mild everyday feelings, therefore, are intertwined with exchange. Positive emotions include excitement, pleasure, pride, and gratitude, and negative emotions include sadness, shame, and anger. Second, social exchange is a quintessential joint activity, but the nature and degree of jointness varies. Interdependencies embedded in exchange structures determine the jointness of the exchange task. My theory argues that, contingent on the exchange structure, emotions or feelings from exchange influence how actors perceive and feel about their shared activity, their relation, and/or their common group affiliations. With higher degrees of jointness, the emotions experienced by actors in exchange should make the relational or group context more salient as a target for cognitions and feelings. Emotions, in this sense, contribute to the "objectification" of relations and groups (Berger and Luckmann 1966; Collins 1981).

The affect theory steps off from and extends the "theory of relational cohesion" developed and tested in a series of experiments over the last 10 years (Lawler and Yoon 1993, 1996, 1998; Lawler, Thye, and Yoon 2000). The focus of this work was understanding the development of commitment to exchange relations and, in particular, the effects of repeated exchange among the same actors. Several experiments clearly demonstrate that repeated exchange with the same others generate positive emotions that, in turn, promote perceived cohesion and commitment behavior (e.g., staying in the relation, providing unilateral gifts). A recent study shows further that an uncertainty-reduction process operates distinct from and independent of the emotional-affective process, suggesting dual processes for emotion and uncertainty reduction (Lawler et al. 2000). My affect theory of social exchange focuses exclusively on the emotional/ affective process in order to broaden and deepen theorizing of the emotional effects of exchange. 
Lawler and Thye (1999) recently showed the variety of roles emotions can play in social exchange. Emotions are an integral part of the normative context of exchange and often managed carefully by actors (Hochschild (1979, 1983). In fact, emotion management accounts for why emotions are often hidden from view in social exchange contexts and, for that matter, other task-oriented, instrumental settings. Power or status differences are known to generate different emotions (Kemper 1978; Ridgeway and Johnson 1990) and to have important effects on the interaction of low- and high-status or power actors (Lovaglia and Houser 1996; Willer, Lovaglia, and Markovsky 1997). Emotions are subtle signals to actors about their own responses in interaction-as shown by affect control theory (Heise 1979) - and when expressed, they provide information on the intentions or orientation of others (Frank 1988). The affect theory of social exchange complements these other approaches. It analyzes how actors experience, interpret, and respond to their own emotions and feelings produced by successful or unsuccessful exchange efforts; and, it aims to explicate a causal process through which the emotions generate order and solidarity at the relational, group, or network level.

Two interrelated questions are posed by the theory: (1) Under what structural conditions will exchange produce emotions and feelings? (2) Under what conditions will this emotion be attributed to social units (relations, groups, organizations) and, therefore, generate collectively oriented behavior? The core idea of the proposed theory can be expressed as follows (see Lawler and Thye 1999, pp. 237-38): Structural interdependencies among actors produce joint activities that, in turn, generate positive or negative emotions; these emotions are attributed to social units (relationships, networks, groups) under certain conditions, thereby producing stronger or weaker individual-to-collective ties; and the strength of those group ties determines collectively oriented behavior, such as providing unilateral benefits, expanding areas of collaboration, forgiving periodic opportunism, and staying in the relationship despite alternatives. The following pages explain how the theory relates to extant exchange theory and research.

\section{BACKGROUND}

Exchange theory assumes that actors face substantial degrees of ambiguity and uncertainty-about what potential partners value, the utility of different exchanges to them, and what exchanges are being made between others in the exchange network (see Molm and Cook 1995). Social exchange is essentially about how actors jointly deal with and respond to these uncertainties and ambiguities. It has been theorized that exchange 


\section{American Journal of Sociology}

theory's actors respond both to past rewards, costs, and punishments and also to anticipated future rewards, costs, and punishments (Molm and Cook 1995), that is, they are both backward looking and forward looking (Macy 1993). However, they are not necessarily fully rational profit maximizers (see Molm and Cook 1995). The goal of the actors is to generate more valued goods, profit, and utility than they currently have, which makes it possible for them to consummate exchanges that provide each with more benefit than otherwise, but that are suboptimal (e.g., Macy 1993). ${ }^{2}$

Given the uncertainty built into social exchange contexts, actors face serious, irresolvable information deficits. Such conditions should enhance the emotional reactions when they succeed or fail at using exchange opportunities to deal with these uncertainties. Classic exchange theorists attributed some import to emotions through concepts such as sentiment (Homans 1961), comparison level (Thibaut and Kelley 1959), and intrinsic attraction (Blau 1964), but emotions were subsidiary and undertheorized. In the last 30 years, however, emotion as a relevant phenomenon to exchange theorizing has receded further into the background. This is in part due to Emerson's seminal theoretical work (1972a, 1981). He elaborated and strengthened the operant/reinforcement foundation for exchange and made social structures (networks) the central problem, but in the process rendered emotions epiphenomenal or irrelevant. A similar trend is evident in the work of Thibaut and Kelley. They gave more attention to emotional aspects of exchange in their early work (1959) than in their later elaboration, where cognition became more central (Kelley and Thibaut 1978).

In contemporary exchange theorizing, individual actors are assumed to be not only self-interested but also unemotional or emotionally vacuous (Lawler and Thye 1999). This metatheoretical theme has reached its zenith in theory and research on exchange networks, from that of Emerson and his colleagues (Cook and Emerson 1978; Cook et al. 1983), to that of Markovsky, Willer, and their colleagues (Markovsky et al. 1988, 1993;

\footnotetext{
${ }^{2}$ Among economic theories or perspectives, social exchange theory is closest to transactions-cost economics (Williamson 1981, 1985; North 1990). Williamson (1985) and North (1990) assume bounded-rational actors, who are "intendedly rational" but imperfectly so, and who contract with one another to deal with uncertainties. When transactions are frequent, transaction-specific assets tend to emerge, and thereby generate "bilateral trading" relationships (Williamson 1985, p. 30) or "personalized exchange" (North 1990). My affect theory helps explain such emerging relationships, by adding an emotional dimension and suggesting how relations can take on intrinsic or expressive value.
} 
Skvoretz and Willer 1993; Willer et al. 1997). ${ }^{3}$ Emerson's reorientation of exchange theory toward networks of relations rather than isolated dyads stimulated a vast and impressive corpus of theory and research. That research shows in detail how exchange networks affect the distribution of rewards across individuals in different positions (Molm and Cook 1995) and also how actors' choice of partner among a set of exchange opportunities generates some exchange relations and not others (e.g., Cook et al. 1983; Markovsky et al. 1988; Skvoretz and Willer 1993; Friedkin 1992).

Rational choice and reinforcement processes are the micromediating mechanisms in contemporary exchange theorizing. The effects of network structures on action (strategy) are through either (1) the rational, dispassionate choices made by actors about who to exchange with and about what constitutes acceptable terms to offer (Willer and Anderson 1981) or (2) the reinforcement contingencies developed over time in the exchange process (Macy 1993; Molm 1987, 1994; Molm and Cook 1995). Cognitive constructs about payoffs and incentives operate as an adjunct to these (see Cook and Whitmeyer 1992). Risk and trust are especially prominent in exchange theorists' effort to address departures from strict reinforcement or rational choice processes and to refine or qualify structural predictions (Molm 1994, 1997). Recently, some work by network exchange theorists has included emotions as well as cognitions (Willer et al. 1997).

My affect theory proposes a third micromediating mechanism that pulls elements from both a rational choice and reinforcement perspective. It is informed by the larger psychological and sociological literature on emotions, in particular the work of Collins (1981), Kemper (1978, 1987), Weiner (1985), and Izard (1991). Emotions are defined as positive or negative evaluative states with physiological and cognitive components (Lazarus 1984; Kemper 1978; Izard 1991; Clore 1994). Emotions may be transitory or enduring, objectless or object focused, and of varying intensity. For our purposes, I distinguish emotion and sentiment. Emotions are global or specific, transitory feelings-positive or negative-that constitute an internal response to an event or object (Weiner 1986; Frijda 1993; Kemper 1978). ${ }^{4}$ Sentiments are enduring affective states or feelings about one or

\footnotetext{
${ }^{3}$ Research on equity and justice includes stronger emotional features than found in the exchange-network tradition, but emotions enter primarily as mediators of behavioral reactions to inequity. Sociological approaches emphasize cognitive models that analyze justice judgments or evaluations (Hegtvedt and Markovsky 1995).

${ }^{4}$ Clore et al. (1987) distinguish emotions based on three types of cognitive focus giving rise to them: events, actions of agents, or aspects of objects. Events generate pleasure/ displeasure; agents approval/disapproval; and objects liking/disliking. Social exchange, in these terms, is an event giving rise to pleasure or displeasure. This is generally consistent with my affect theory of exchange.
} 
American Journal of Sociology

more social objects. Relations and groups are social objects, as are self and other. Sentiments link emotions (feelings) to social units (Gordon 1981). This relational aspect of sentiments is drawn from Homans (1961), leaving behind his behaviorist slant.

Following Weiner (1985), my affect theory distinguishes global emotions and feelings from those that are specific and focused on a given social object (specific emotions). Global emotions are "primitive" and have ambiguous sources. Specific emotions are attached to or associated by the actors with particular objects. A goal here is to theorize the link of everyday emotions that are global and transitory to the more enduring affective sentiments about social objects such as relationships, groups, and networks. A key theoretical question is When does social exchange lead actors to associate global emotions with specific social objects-such as self, other, a relationship, or group_-and, as a result, develop more enduring positive or negative feelings about those social objects? Research documents that social exchange produces global feelings of satisfaction or dissatisfaction (Molm 1994; Lawler and Thye 1999). The affect theory assumes that actors are motivated to interpret such emotions and theorizes that jointness of the exchange activity points them in the direction of social units. In the following section, I present core assumptions of the theory, a conceptual framework connecting different emotions to different social objects (e.g., self, other, social unit), and a set of testable propositions.

\section{THE AFFECT THEORY}

The affect theory of social exchange articulates general theoretical principles that are intended to apply to a wide range of contexts-for example, pleasantries or compliments by acquaintances, support or advice among coworkers, information flows (gossip) among organizations, contracting between firms and suppliers or between labor and management, and trading relations among nations. The theory assumes a network context with three or more actors who have an opportunity to exchange valued behaviors, goods, or outcomes. Exchanges are dyadic and dyads are "connected"; that is, exchange in a given dyad affects or is affected by exchanges in one or more other dyads (Emerson 1972b, 1981). The individual actors make decisions about whether to exchange, with whom to exchange, and under what terms. They do this repeatedly over time with the same others, because the network structure creates recurring opportunities or constraints on who can exchange with whom. As implied, the focus is exchanges that are ongoing, recurring, and subject to renegotiation 
"at will," meaning that "spot" exchanges among strangers or buyers/sellers in a market are excluded from the scope of this theoretical analysis.

Theoretical Assumptions

There are five foundational assumptions of the affect theory of social exchange:

Assumption 1.- Social exchange produces global emotions or feelings, along a positive-to-negative dimension.

ASSUMPTION 2.-Global emotions from social exchange are internal (self) reinforcing or punishing stimuli.

Assumption 3.-Actors strive to reproduce global positive emotions and avoid global negative emotions experienced as a result of social exchange.

AsSuMPtion 4.-The global emotions produced by social exchange trigger cognitive efforts to understand the sources or causes of global feelings; more specific emotions, tied to social objects, result from this attribution process.

Assumption 5.-In the case of joint tasks, such as social exchange, actors interpret and explain their global feelings partly with reference to social units (e.g., relations, networks, or groups).

The five assumptions are informed by recent theory and research on commitment in exchange (Lawler and Yoon 1993, 1996, 1998; Lawler and Thye 1999; Lawler et al. 2000) and serve as the backdrop for propositions of the affect theory of social exchange. Each assumption is discussed below.

Global emotions or feelings essentially involve "feeling good" or "feeling bad" (Russell, Weiss, and Mendelsohn 1989). These are immediate, internal, involuntary events produced by the results of an exchange process (Weiner 1985). If exchange is consummated successfully, individuals feel good about solving a task; if the exchange is unsuccessful, they feel bad about not solving it (assumption 1). This general idea receives consistent empirical support in research on exchange (Molm 1991; Lawler and Yoon 1996; Lawler et al. 2000). "Feeling good" and "feeling bad" can be construed as special classes of reward and punishment, both internal and self-induced (Bandura 1997) (assumption 2). Bandura has used the term "self-reinforcement" to distinguish such internal stimuli from those that are external to the actor and also to make the point that these are analytically independent from other forms of reinforcement and punishment.

Emotions are motivating because "feeling good" is positively valued in itself and "feeling bad" is negatively valued in itself. Izard (1991, p. 43) states "once an emotion is activated, whether by sensory data (e.g., pain) or by cognitive processes (e.g., appraisal, attribution), even if it is a re- 


\section{American Journal of Sociology}

sponse to an event, it then becomes an organizing and driving force in subsequent thought and action" (assumption 3). Emotions are responses to stimuli but also stimuli that cause other responses. Many psychologists have argued or shown that emotions are based on cognitive appraisals of some minimal sort (Lazarus 1984; Clore et al. 1987) and also that they generate further cognitive appraisal through which actors understand and interpret the connections between their feelings and their experiences. Global feelings from exchange provide actors "a read" on their own responses (see Heise [1979] for a related idea), but the vagueness of these global emotions is a stimulus for cognitive-interpretive work (assumption 4). ${ }^{5}$

Weiner's (1986) attribution theory of emotion provides a framework for understanding why global emotions generate cognitive-interpretive processes. In Weiner's (1986) theory, "primitive" emotions are global responses to the outcomes of an interaction-that is, they are "outcome dependent." Such emotions are not based on interpretations or attributions-that is, they are "attribution independent." Primitive, global emotions can be construed as internal, first-level, involuntary responses, felt and perceived by the actors but sufficiently ambiguous to motivate an attribution process (Weiner 1986). More specific emotions, such as gratitude/anger toward the other or pride/shame in self are a result of efforts to interpret the source or cause of such global emotions. Thus, whereas global emotions are stimulus based and not under the control of the actor, they unleash an attribution process that generates more specific, object-focused emotions (Weiner 1986). This is a key point of the affect theory of exchange, and I return to it later.

Social units-relations and networks-are potential objects or targets of the global emotions. Assumption 5 indicates that the jointness of exchange tasks leads actors to target social units in their interpretation of the source of global emotions. If positive global emotions are attributed to social units, they should develop stronger affective attachments to the targeted relations or structures; if negative ones are attributed to social units, weaker affective attachments should form.

The five assumptions constitute a single, unified package that suggests how emotions generated by exchange may produce stronger affective attachments to relevant social units. The interrelation of the assumptions

\footnotetext{
${ }^{5}$ The standard view of exchange theorists is that emotions do not provide new information beyond what is contained in the contingencies of reward and punishment, i.e., they are epiphenomenal and lack stimulus properties themselves. If emotions are selfreinforcing (or self-punishing) events, however, emotional effects may add to objective, extrinsic rewards in exchange, compensate for less-than-adequate rewards, or even substitute for extrinsic rewards.
} 
is diagrammed in figure 1. Some links are analytic (definitional), and others are synthetic (propositional).

The fundamental implication of the assumptions, as a whole, is that positive emotions produced by exchange should increase solidarity effects on relations and groups, and negative emotions should decrease solidarity effects (Cook and Emerson 1984; Kollock 1994; Lawler and Yoon 1996; Lawler and Thye 1999; Lawler et al. 2000). Solidarity is defined here as the strength and durability of person-to-group and person-to-person relations (Parsons 1951; Hechter 1987). Behavioral manifestations or indicators of solidarity include the following: (1) Expanding areas of collaboration among actors (i.e., adding new exchange domains), even though these make actors more dependent on each other and more vulnerable to opportunism. (2) Exchanging unilateral benefits (e.g., gifts) that, when provided, have no explicit demand for or expectation of reciprocity. (3) Accepting more incomplete contracts, that is, ones with more ambiguities, looser accountability rules, and fewer safeguards. (4) Forgiving costly behaviors or isolated instances of opportunism. (5) Remaining in an existing relation or group despite equal or better alternatives elsewhere. To the degree that such behaviors occur, the social unit in question has taken on expressive value in itself. Emotional processes, in this sense, are a key foundation for microsocial orders. ${ }^{6}$

\section{Emotion and Social Objects}

The theory connects the joint task of exchange with a social unit. The social unit is a social object that is real to actors (Berger and Luckmann 1966). To theorize the connections of the joint task and emotions directed at a social unit, we need a simple framework to identify the main social objects in exchange and the emotions likely to be associated with each object. Four social objects are assumed: $(a)$ task, $(b)$ self, $(c)$ other, and $(d)$ social unit. The task is embedded in the form of exchange or exchange structure. The most fundamental structures identified by exchangenetwork theorists are productive, negotiated (restricted), nonnegotiated (reciprocal), and generalized (see Ekeh 1974; Emerson 1981; Molm 1994; Molm and Cook 1995); each structure entails a somewhat different task, which I analyze shortly. Self here refers to inferences from exchange about oneself (i.e., situational self-evaluations). Other refers to inferences about

\footnotetext{
${ }^{6}$ In a recent study, Lawler et al. (2000) observed that an uncertainty-reduction process operates independently of an emotional/affective process to produce cooperation in an $N$-person prisoner's dilemma, whereas an emotional/affective process produces unilateral gift giving. The implication is that some forms of solidarity-related behavior may be generated by uncertainty reduction and others by emotion or affect.
} 


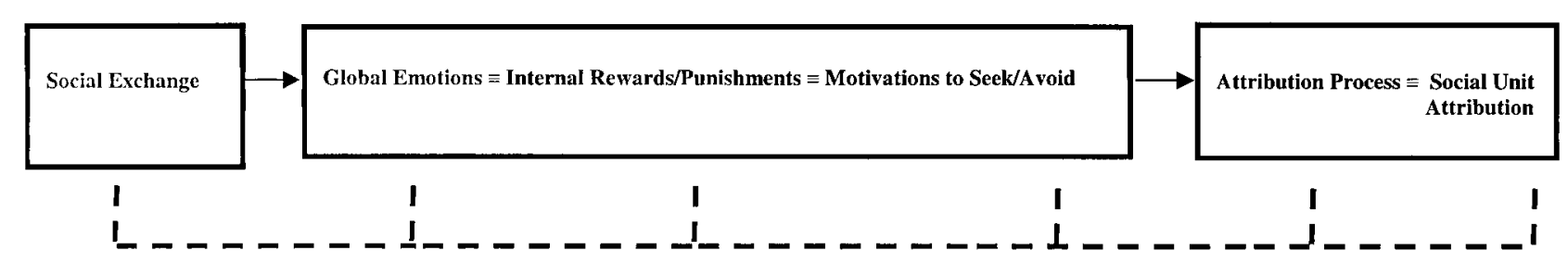

Al

A2

A3

A4

A5

FIG. 1.-Interrelation of assumptions 
the other person with whom one is attempting to exchange (i.e., situational evaluations of other). Finally, the social unit is the bounded social entity perceived by actors as the principal context for the exchange; this can be an exchange relation, network, or group.

Table 1 presents a conceptual scheme tying different emotions to different objects. This scheme pulls ideas from a variety of psychological theory (Larsen and Diener 1992), especially Weiner's (1986) attribution theory and Russell et al.'s (1989) “affect grid.” Feelings of pleasantness or unpleasantness are the global emotions. Pleasant feelings include interest (i.e., excitement, enthusiasm) and joy (i.e., satisfaction, comfort, relaxation); unpleasant feelings include stress or sadness (Russell et al. 1989). Interest and stress entail higher activation or arousal than joy or sadness (Larsen and Diener 1992). Following Weiner (1986), these global feelings form without much, if any, cognitive work, but they, in turn, produce an attribution process designed to understand their causes-that is, the global emotions are outcome dependent and attribution independent (see Lazarus [1984] for related discussion).

The other emotions in table 1-those attached to self, other, or social units-are mediated by the attribution process. On the positive side are pride in self and gratitude toward the other; on the negative side are shame in self and anger toward the other. If actors attribute pleasant feelings from the exchange task to their own behavior, they feel pride; if they attribute pleasant feelings to the other, they feel gratitude toward that other. If the unpleasant feelings from failure at the exchange task are attributed to self, shame is the likely emotion; if it is attributed to the other, anger is the likely emotion. In some contexts, emotional ambivalence may occur, involving a complex mixture of pride and shame toward self or anger and gratitude toward the other. In other contexts, certain emotional responses may be dominant features of the situation (Scheff 1990). Attributions to social units entail tacit or explicit relational/group affiliations, and the relevant emotions are termed affective attachment or detachment (alienation).

Attribution research reveals a tendency toward self-serving (hedonistic) attributions; that is, individuals tend to attribute good events or behavior internally and bad events externally (to the other or situation; see Weiner 1985). In social exchange, individuals therefore may give themselves more credit for positive feelings from exchange and the other more blame for negative feelings from failure to exchange. The mutual crediting-of-self for pleasant results and blaming-of-other for unpleasant results can be construed as a significant threat to exchange relations. The attribution of positive emotion to social units may counter this threat and mitigate "social order" problems implicit in self-serving (hedonistic) biases in attribution processes. The attribution of negative emotion to the social unit 
American Journal of Sociology

TABLE 1

Emotions Directed at Each Овject

\begin{tabular}{lll}
\hline \hline & \multicolumn{2}{c}{ Valence of Eмотіол } \\
\cline { 2 - 3 } Social Овјест & \multicolumn{1}{c}{ Positive } & \multicolumn{1}{c}{ Negative } \\
\hline Task $\ldots \ldots \ldots \ldots$ & Pleasantness & Unpleasantness \\
Self $\ldots \ldots \ldots \ldots$ & Pride & Shame \\
Other $\ldots \ldots \ldots$ & Gratitude & Anger \\
Social unit $\ldots$ & Affective attachment & Affective detachment \\
\hline
\end{tabular}

may promote the preservation of exchange relations by reducing mutual shame in self and anger toward each other.

Attribution theory in psychology has focused almost exclusively on the inferences made about a person from that person's individual behavior (Kelley 1967; Weiner 1985). In attribution terms, ascribing emotions to relations or groups entail a situational attribution. The contrast of dispositional (internal to the person) versus situational (external to the person) attributions has framed and organized nearly all work under the rubric of "attribution theory" (Hewstone 1989). Situational attributions include attributions of an actor's behavior to chance, to luck, to a task, to a relationship with another, or to larger groups or organizations. This undifferentiated and open-ended notion glosses over and conflates important features of the situation. Moreover, the dispositional (internal) and situational (external) dichotomy breaks down in group or interaction settings where the tasks accomplished by actors are joint ones and where their individual contributions are difficult to distinguish or separate (see Hewstone [1989] for a similar view and for relevant empirical evidence). This makes the attribution of individual emotions to social units an important issue in interaction settings.

I argue that-because global emotions are valued, self-reinforcing (or self-punishing) stimuli, yet not controlled by those who feel them-actors attempt to understand and control underlying situational conditions or causes. This implies a more fine-grained, nuanced understanding of the situational correlates of feelings than that suggested by the standard internal-external dichotomy assumed in attribution theory and research. A plausible conjecture is that social relations and groups offer attractive explanations for actors (whether accurate or not), because social units are often stable features of the situation. I posit a social-unit attribution process whereby actors attempt to understand the social foundations of global emotions from the task. ${ }^{7}$

\footnotetext{
${ }^{7}$ In the attribution literature, some attention has been accorded inferences about individuals from social interaction, rather than from individual behavior (see Hewstone
} 
Affect Theory

Theoretical Propositions

The object-emotion links raise several questions. What features of joint exchange tasks set the stage for social-unit (relational or group) attributions for emotions? How do various types of exchange structure (e.g., negotiated vs. generalized) affect these features of the task and therefore the emotion produced? What are the conditions under which social unit attributions for the emotion are likely to override the tendency toward self-serving attributions of credit/blame for success/failure at the exchange task? Given multiple social units, which ones are most likely to be targets for emotional attributions? These questions organize the propositions of the affect theory.

Properties of joint exchange tasks.-A joint task is one that can only be completed with one or more others. None of the actors can complete the task alone and, therefore, a condition of interdependence is assumed. How the individual behaviors or contributions to the task effort are connected or put together can vary considerably. The affect theory of social exchange emphasizes two fundamental dimensions of jointness. First, in joint tasks, actors' individual contributions are not as easily identifiable or separable from the contributions of others than in other tasks. Nonseparability is a structural dimension of joint tasks. This property was used by Williamson (1985, pp. 245-47) to theorize what organizations of labor will produce relational-team governance structures with a "we are all in this together" theme. Second, joint tasks make it difficult for actors to give total credit to themselves for positive feelings from task success or total blame to the other for negative feelings from task failure. Their interdependence with one or more others should lead them to not only take account of the other's role in task success but also to share credit or blame. This means that joint tasks, such as exchange, have the potential to promote a sense of shared responsibility for task success/failure and the emotions that result.

Joint tasks that generate shared responsibility are also likely to generate a sense of socially mediated self-efficacy-meaning that an individual's self-efficacy is tied to collective efficacy via a relation or group. Successful exchange may foster a variety of efficacy-related perceptions: for example, "We can do profitable work together," "We can do things that I cannot do alone or with others," or "When we get together, things happen," and so on. These also reflect a sense of shared responsibility. Research demonstrates that perceptions of self-efficacy produce positive emotions (joy, elation, pride), and its absence produces negative emotions (sadness, de-

1989 for a review), but there is little research on attributional inferences about relationships or groups from social interaction. Some indications of this are found in work on close relationships (see Duck 1988) and social identity (see Tajfel and Turner 1986). 
American Journal of Sociology

pression, shame) (Deci 1980; Izard 1991). Self-efficacy helps explain the impact of shared responsibility on attachments to social units.

The properties of joint tasks are interwoven. The most fundamental basis for perceptions of shared responsibility - and by implication socially mediated self-efficacy - is how identifiable and distinctive individual contributions are to the task. To the degree that each individual's involvement in, contributions to, or influence over the results of exchange are not clearly distinguishable or separable, actors should perceive a joint, shared responsibility for success or failure at the exchange task. This reasoning leads to two core propositions of the theory:

PROPOSITION 1.-The greater the nonseparability of individuals' impact on task success or failure, the greater the perception of shared responsibility.

PROPOSITION 2.-The greater the perception of shared responsibility for success/failure at a joint task, the more inclined actors are to attribute resulting global and specific feelings to social units (i.e., relations, networks, or groups).

Exchange structure and emotion.-Exchange structures can increase or decrease perceptions of shared responsibility, because of differences in the nonseparability of individual task behaviors across structures. Sociological theories of exchange distinguish four forms or types of exchange structure, each entailing a distinct joint activity (see Emerson 1972b, 1981; Ekeh 1974; Molm 1994; Molm and Cook 1995). These are (a) productive exchange, that is, coordinating efforts or combining resources to generate a joint good; (b) negotiated exchange, that is, negotiating an explicit agreement or the terms of a trade; $(c)$ reciprocal exchange (sequential, often tacit, giving of benefits across time) and $(d)$ generalized exchange (providing unilateral benefits to one actor or member of a network or group while receiving them from one or more other members; see Emerson 1981; Molm and Cook 1995). Productive exchanges are actor-to-group and involve a common target and source of benefit (i.e., the collective endeavor); negotiated and reciprocal exchanges are actor-to-actor (i.e., direct exchange); and generalized exchanges are indirect in that to whom an actor gives benefit is not the same actor from whom he or she receive benefit. These forms of exchange are diagrammed in figure 2 .

Consider the example of scholarly exchanges among three professors: $\mathrm{A}, \mathrm{B}, \mathrm{C}$. If $\mathrm{A}$ and $\mathrm{B}$ give each other a paper they are working on and agree to have lunch to discuss each other's work, this is a negotiated exchange in which the terms are the time and care devoted to each other's paper. Coauthorship by any two or all three, in which each contributes specific talents or knowledge, illustrates a productive exchange-that is, they give and receive from the collective endeavor or product. A reciprocal exchange would occur if A asks and receives feedback from B on a paper 
Affect Theory

\section{Productive}

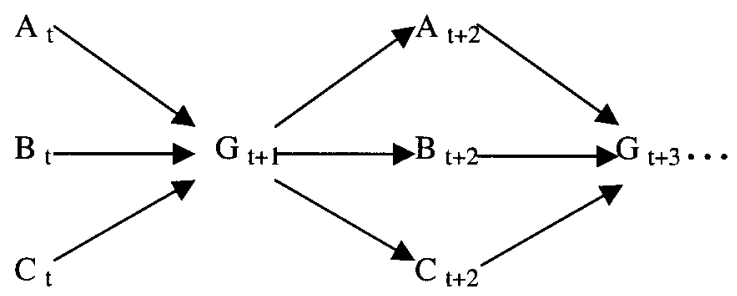

Direct Exchange

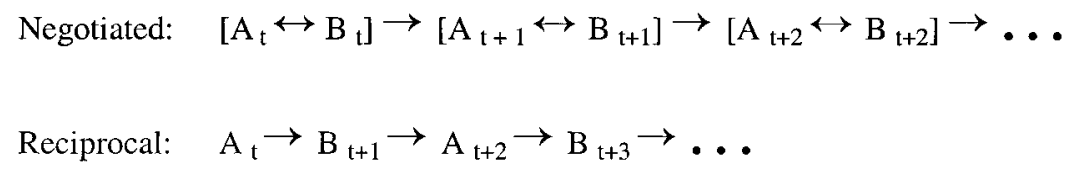

Indirect Exchange

$$
\mathrm{A}_{\mathrm{t}} \rightarrow \mathrm{B}_{\mathrm{t}+1} \rightarrow \mathrm{C}_{\mathrm{t}+2} \rightarrow \mathrm{A}_{\mathrm{t}+3} \rightarrow \mathrm{B}_{\mathrm{t}+4} \rightarrow \ldots
$$

Fig. 2.-Forms of social exchange; A, B, and C refer to group actors and $\mathrm{G}$ to group product (see Molm 1994).

with no expectation that B will comment on one of A's paper, but later on B asks for and receives comments on a paper from A. An indirect, generalized exchange would occur if over time A comments on B's paper, B comments on C's paper, and C comments on A's paper. Each person receives comments on a paper from some other and each person gives comments to another, but the actors in these pairs are not the same persons. The affect theory of social exchange sheds light on when and how these different forms of exchange generate (1) global feelings of pleasantness or unpleasantness, (2) perceptions of shared responsibility, and (3) an attribution process generating affective attachments to social units.

The comparison of different structures of exchange is a unique aspect of the affect theory. Recent theorizing and research on emotion and exchange has focused on a single form of exchange structure. Tests of the theory of relational cohesion have been conducted in negotiated exchange 
American Journal of Sociology

(Lawler and Yoon 1993, 1996, 1998), as have some initial tests of power differences on emotions (Willer et al. 1997). Molm, Peterson, and Takehashi (1999) have shown corresponding effects on emotion in reciprocal (nonnegotiated) exchange. Most recently, a study of productive exchange in three-person groups demonstrates the effects of repeated success at exchange on positive emotions and on group cohesion (Lawler et al. 2000). The affect theory of social exchange is the first attempt to theorize the distinct emotional effects of different exchange structures.

Productive exchange is a "conjunctive" task, that is, one with a single socially produced event or good that occurs only if members perform certain behaviors (Molm 1994; Molm and Cook 1995; Lawler et al. 2000). The potential for productive exchange exists when cooperation provides actors the greatest individual benefits and the main issue is coordination. The prototype is a partnership in which two or more actors bring something specific to a collective endeavor and the whole of what they produce is greater than the sum of the parts. Examples of this type of partnership include a nuclear family eating a meal together, three universities combining resources to initiate a new educational program that none can launch alone or in conjunction with just one other, three scholars coauthoring a paper, and several neighbors organizing a night watch in response to a series of burglaries in the area.

Productive exchange entails higher degrees of interdependence than other forms of exchange, an incentive structure that not only favors cooperation and exchange, but also produces coordination problems that make exchange problematic (see Lawler et al. 2000). It is the most grouporiented form of exchange and likely to have the strongest emotional/ affective consequences for cohesion and solidarity (see Lawler et al. [2000] for supporting evidence). Productive exchange tasks have the greatest degree of nonseparability, produce the greatest degree of shared responsibility, and generate the strongest feelings of pleasantness in the case of success at exchange, and unpleasantness in the case of failure. Other exchange structures undercut these effects due to countervailing negative feelings or a smaller sense of shared responsibility.

The group product can be a private good shared only by members of the group or a public good that has the potential for free riding. In the private-goods case, contributions by all are necessary for the benefit to occur to any of them, and actors know when someone fails to contribute and who it was. In the public-goods case, there is a threshold at which the good is produced and less, if any, knowledge of who fails to contribute. All things being equal, jointly produced private goods will generate a stronger sense of shared responsibility than jointly produced public goods because of the free-rider problem in the latter (Lawler et al. 2000).

Negotiated exchange involves an explicitly contractual agreement in 
which actors agree to terms of a trade and these agreements are binding. Conceptually, the group-level outcomes $(G)$ in negotiated exchange are the average of each negotiator's $(A, B)$ offers or demands; that is, $A+$ $B=G$. Because the exchange is negotiated explicitly and each actor's consent is necessary for the exchange to be consummated, the jointness of the activity is highly salient and the sense of shared responsibility should be relatively strong. The behaviors or contributions of actors to the task have both separable (i.e., distinct offers by each) and nonseparable (i.e., the conjoint effects of their offers) features. Thus, the process specified by propositions 1 and 2 should occur, but not be as strong as in the case of productive exchange.

Research on negotiated exchange has revealed strong support for the notion that exchange produces positive emotions (pleasure-satisfaction) and indicates this is more likely under equal than unequal structural power (Lawler and Yoon 1993, 1996, 1998). The implication is that successful exchange under equal power tends to generate a greater sense of shared responsibility for the exchange and for the positive feelings it produces. Under unequal power, actors tend to blame each other for failure, generating mutual anger; if agreements occur, positive feelings are reduced by the fact that advantaged and disadvantaged actors experience differing degrees of pleasure-satisfaction (Lawler and Yoon 1993; Willer et al. 1997). Self-serving attributions should be stronger in unequal power than equal-power relations.

Negotiated exchange has the potential to produce conflicting emotions or emotional ambivalence, due to the fact that its mixed-motive character is salient. For example, pride in self for successful exchange may be combined with some "shame in self" for not reaching an even better agreement; gratitude toward the other for what he or she gave occurs along with some anger that they did not give more. In the case of failure to exchange, attribution theories suggest that anger toward the other may exceed the shame to self. Importantly, if exchanges are explicit, offers can be compared easily, and actors are sensitive to departures from equality. Successful exchanges may produce the global ups or downs, as predicted by the theory, but emotional ambivalences are likely to reduce the effects of these emotions on group relations. For these reasons, the sense of shared responsibility should be lower in negotiated than in productive exchange.

Reciprocal exchange involves sequential, nonnegotiated, unilateral rewards that are provided without an explicit expectation of reciprocity (Molm 1994; Molm et al. 1999). Tacit, informal understandings replace the explicit agreements of negotiated exchange. Exchanging favors, assisting with job tasks, invitations to dinner are all examples of reciprocal exchange. Each actor benefits individually from what the other provides them and, as in negotiated exchange, the effects of each actor are additive 
American Journal of Sociology

at the relational or group level. Providing benefits to another at a given point in time creates an implicit obligation to reciprocate when asked, but how, what, and when something is to be given in return is left open. Reciprocal exchange entails more uncertainty and risk than negotiated exchange, and consequently trust is especially important here (Molm 1994; Molm et al. 1999).

In reciprocal exchange, the contributions of each actor are separable and distinguishable, given the time lapse between giving and receiving. Therefore, perceptions of shared responsibility for the exchange should not be as strong as for negotiated or productive exchange. The fact that the nonseparability of individual contributions and shared responsibility are lower than in negotiated exchange suggests that successful exchange produces weaker positive emotions in the reciprocal case than in the negotiated case. This is a paradoxical inference, because strong and close relations tend to involve reciprocal exchange and, in fact, recent evidence shows that commitment is greater in reciprocal than in negotiated exchange relations (Molm et al. 1999).

The solution to this paradox lies in how global emotions are produced in negotiated versus reciprocal exchange. In negotiated exchange, the result of an exchange process produces global emotions that are felt and interpreted by actors. In reciprocal exchange, if A gives something of value to $\mathrm{B}, \mathrm{B}$ feels gratitude but gives nothing in return. Yet $\mathrm{B}$ can signal the giver of positive future intent by expressing gratitude (see Frank 1988). This acknowledgement affirms a common definition of the situation and generates a measure of pride on the part of the giver-that is, a gift by A produces an expression of gratitude by $\mathrm{B}$ that in turn generates pride in A. Thus, giving behavior becomes important, not just because of future receiving, but because giving itself produces an internal reward (pride) mediated by the other's immediate reaction. The exchange of benefits itself produces little emotional response, because of the time lags between giving and receiving, but the specific emotions expressed by the receiver and felt by the giver should generate global feelings of pleasantness or unpleasantness. In other words, emotions expressed as an immediate response to a gift "complete" a joint action (gift by one, emotion expressed by the other) similar to that which underlies negotiated exchange. Reciprocal exchange, therefore, should foster stronger perceptions of shared responsibility than would be expected, based on the separability of individuals' giving behavior, but still weaker than negotiated exchange.

Finally, generalized exchange is indirect rather than direct. Unilateral benefits are provided to another, as in reciprocal exchange, but the giver at time 1 receives a benefit from a different actor at time 2, for example, $\mathrm{A}$ gives to $\mathrm{B}$ who gives to $\mathrm{C}$ who gives to $\mathrm{A}$. The givers and receivers do not directly exchange with one another, so the exchange has an im- 
personal character (see Molm and Cook 1995). The prototype is a chain network in which there are unilateral flows of benefit, often forming a closed circle-for example, analyses of the Kula Ring (Ekeh 1974). In a group of scholars this pattern would foster a collegial, helpful environment for each individual actor but not necessarily forge strong ties among any particular subset of actors. Such collective effects indicate that generalized exchange has an element of productive exchange. Like productive exchange, interdependencies among the actors are high, and the coordination of their individual behaviors is a key problem. Yet, generalized exchange entails separable individual contributions to the collective endeavor, and it is not likely to endogenously generate a strong sense of shared responsibility for exchange. The collective or group effects occur on an objective, but not a subjective, level.

The group-level effects of generalized exchange lead Ekeh (1974) to argue that generalized exchange is a fundamental underpinning of social order. It generates higher levels of group solidarity to the degree that mutual trust is present among the actors, trust that others will "discharge their obligations to the enrichment of society rather than for their exclusive narrow self interest" (1974, p. 59). Such trust presupposes constraints from a larger network of relationships; that is, it is relationally-rather than transactionally-based. ${ }^{8}$ Ekeh argues that, in the case of direct exchange (i.e., what he terms "restricted exchange"), a quid pro quo or transactional mentality renders order and solidarity more brittle and tenuous. My argument is that indirect exchange relations are fragile because they do not have the emotional/affective foundation that can develop in either productive or direct forms of exchange. Indirect exchanges lack the interpersonal component as well as an explicit or salient joint product.

Table 2 summarizes the comparisons between the forms of social exchange. Three differences are important: (1) the degree of jointness in the exchange task (i.e., nonseparability of individual behavior or contributions); (2) the strength or intensity of the emotional response to success or failure; and (3) whether actors are likely to perceive a shared responsibility for the emotions produced by performance of the exchange task. Productive exchange is highest on these dimensions, direct exchange (negotiated and reciprocal) second, and indirect (generalized) last. Three propositions capture the main argument:

Proposition 3.-Productive exchange relations produce stronger global

${ }^{8}$ It should be noted that Ekeh (1974) distinguishes several types of generalized exchange. The form I refer to here is what Ekeh calls "chain generalized"; what I term productive exchange is comparable to what Ekeh terms "group focused net generalized exchange." 
American Journal of Sociology

TABLE 2

Comparison of EfFects of Exchange Structures

\begin{tabular}{clll}
\hline \hline Structure & Nonseparability & \multicolumn{1}{c}{$\begin{array}{c}\text { Perception of } \\
\text { Shared } \\
\text { Responsibility }\end{array}$} & Global Emotions \\
\hline Productive $\ldots$ & High & High & High \\
Negotiated $\ldots$ & Medium & High & Medium to high \\
Reciprocal $\ldots$ & Low & Medium to high & Medium \\
Indirect $\ldots . .$. & Low & Low & Low \\
\hline
\end{tabular}

feelings and stronger perceptions of shared responsibility than direct or indirect (generalized) exchange relations.

PROPOSITION 4.-Direct exchange relations (negotiated and reciprocal) produce stronger global feelings and stronger perceptions of shared responsibility than indirect (generalized) exchange.

PROPOSITION 5.-Comparing direct forms of exchange, negotiated exchange produces stronger global feelings and perceptions of shared responsibility, whereas emotional expressions in the exchange process have these effects for reciprocal exchange.

To summarize, the theory shows why and how the emotional effects of exchange vary across different exchange structures. In productive exchange, the nonseparability of individual contributions and shared responsibility stand out, and thus, the corresponding emotions should be felt more intensely, whether they are positive (in the case of success) and/ or negative (in the case of failure). Negotiated exchange leads to mutually acknowledged agreements (or nonagreements) and, once again, jointness should be highly salient; yet, negotiated exchange promotes a mixture of positive and negative specific emotions about self and other, and individual effects are more easily distinguishable than in productive exchange. Reciprocal exchange, with the varied time lags between giving and receiving, has easily separable individual-level contributions, but in a comparable sense, shared responsibility is produced if there is an exchange of expressed emotions around each unilateral gift. Shared responsibility is structurally produced in negotiated exchange, whereas it is behaviorally constructed in reciprocal exchange. In generalized exchange, the fact of a joint task is not evident unless it is already established and then begins to break down. A sense of shared responsibility would have to be produced exogenously in generalized exchange, rather than through the endogenous process of my affect theory.

Relational and group attributions of emotion.-Relational and group attributions of emotion are a critical link between the global emotions from exchange and solidarity behavior. Based on the theory, relational/ 
group attributions are likely when (1) the exchange relations have a productive form, (2) the results of exchange are jointly produced in such a way that individual contributions or influences are not easily separable, and (3) actors perceive a shared responsibility for the global emotions felt. Relational or group attributions suppress self-serving attribution biases under these conditions by promoting interconnections between individuals' sense of self-efficacy and their sense of collective efficacy; because for actors, self-efficacy is mediated by the relation or group. Social-unit attributions should be strongest when actors' sense of self-efficacy from the task is completely interwoven with their sense of collective efficacy, as is likely under productive exchange. Higher interdependence connotes a stronger structural link between self and collective efficacy; and if actors perceive this, relational/group attributions should dominate self-serving attributions. Proposition 6 states the main point, and proposition 7 predicts the ordering across exchange structures:

PROPOSITION 6.-Relational and group attributions of emotions from exchange are stronger to the degree that (1) the exchanges are productive rather than direct or indirect, (2) the exchange task is joint (high nonseparability), and (3) the task creates perceptions of shared responsibility for global emotions.

PROPOSITION 7.-The strength of relational and group attributions for global emotions is ordered as follows across the four forms of exchange:

$$
\text { productive }>\text { negotiated }>\text { reciprocal }>\text { generalized. }
$$

Molm et al.'s (1999) evidence that reciprocal exchange produces more trust, commitment, and positive affect directed toward the exchange partner than negotiated exchange could be construed as contrary to proposition 7. The relevant social object in Molm's research, however, is the other person, rather than the social unit (relationship); and, in this context, it makes sense that reciprocal exchange would produce emotion directed toward the other person. The explicit jointness of the task in negotiated exchange sets the stage for attributions to a larger social unit (in this case, the exchange relation), without necessarily eliminating attributions to self and other. Evidence from social-identity research reveals that perceptions of a social unit (i.e., groupness) are not mere reflections of how particular others in the situation are perceived, a major point also theorized by George Herbert Mead (1934) in his classic analysis of generalized others. My contention is that negotiated exchange is more likely to create a sense of something larger, beyond the dyadic exchange, than is reciprocal exchange. Cohesion and solidarity should be more impersonal in negotiated exchange and more personal in reciprocal exchange.

Relational or group attributions generate important solidarity-related consequences not only for global emotions but also for specific emotions 
American Journal of Sociology

directed at self and other. If self-serving attributions are dominant, emotions directed at self and other are inversely related - that is, pride in self is negatively correlated with gratitude toward the other. However, if relational/group attributions are strong, pride in self and gratitude toward the other are not zero sum; success at exchange increases both pride by A and A's gratitude toward B. Applied to negative emotions, person A could experience both shame in self and anger toward B. Mutually felt pride/gratitude builds and solidifies relationships, whereas mutually felt shame/anger weakens or tears them apart (e.g., see also Scheff 1990).

To elaborate, consider two individuals, $\mathrm{A}$ and $\mathrm{B}$, who are able to make exchanges on a regular basis under the conditions of proposition 6 . They come to realize that they can accomplish something important together which they each would have trouble accomplishing alone or with other partners. Person A feels pride at solving the exchange problem with another, and A also feels gratitude toward B for being a reliable partner in their joint effort. The pride A feels takes no credit away from B and the gratitude toward B takes no credit away from herself. The fact that each can feel good about themselves (pride), about the other (gratitude), and about their relationship stems from the interweaving of self and collective efficacy. Thus, relational attributions of the global positive emotions essentially foster a sharing of emotional benefits at the level of specific emotions which, in turn, further strengthens attachments to the relevant social unit.

The sharing of emotional benefits, however, does not fully generalize to the "emotional costs" of joint failure. Given a perception of shared responsibility for task failure, relational attributions lead actors to shift some blame or anger to their relationship and away from each other, thinking, for example: "Well, perhaps it's not me, and it's not him; we just don't hit it off or work together well" or "Well, we really blew it here because we didn't see eye to eye on the problem; we need to work on this." Relational effects occur but self-serving biases are not likely to be suppressed to the same degree in the case of shared responsibility for failure at the exchange task. Actors still are likely to feel more anger toward the other than blame to oneself. The following proposition is implied:

Proposition 8.-Relational/group attributions for positive emotions from successful exchange eliminate self-serving biases and equally enhance pride in self and gratitude toward the other; relational/group attributions for negative emotions from failure to exchange reduce, but do not eliminate, self-serving biases, such that the actor feels more anger toward the other than shame in self.

Affective attachments.-The most fundamental solidarity effect of relational/group attributions is to enhance or diminish actors' affective at- 
tachment to the social unit, that is, person-to-group ties (Parsons 1951; Tajfel and Turner 1986. Relational/group attributions for positive emotion increase actors' affective attachment to the social unit, whereas attributions for negative emotions foster affective detachment or alienation. Conditions under which these effects occur can be developed from Weiner's (1985) attribution theory of emotions.

Weiner argues that causal attributions for behavior have emotional effects on actors, depending on three conditions: (1) the locus of causality (internal vs. external), (2) the perceived stability of the cause (i.e., its persistence as a force), and (3) the degree that the cause is controllable by anyone, not just the actors in question. He predicts different specific emotions for each possible combination of these conditions. Of particular relevance for the affect theory of social exchange, attributions of positive acts by another produce gratitude if perceived as "controllable" by the other (i.e., voluntary); whereas negative acts generate anger, if perceived as controllable by the other. Furthermore, if the causes of the behavior in question are stable, then reliable expectations of success or failure form and these, in turn, produce feelings of hopefulness or hopelessness (Weiner 1985, p. 162). Stability and controllability suggest when affective attachment or detachment is likely.

Social units are sources of stability and controllability. If a relation is perceived as a stable source of positive feelings and also as enhancing actors' control over them, the positive impact on affective attachments to that social unit should be stronger than otherwise. The role of socially mediated self efficacy again is implied here. Negative feelings from exchange should heighten affective detachment if the relation is perceived as a stable source of negative feelings and if these are not controllable by the actors. ${ }^{9}$ With repeated success at the exchange task, the actor becomes more and more affectively attached to the relation, and the relation becomes a stronger object of positive value; with repeated failure, a detachment process occurs and the relation loses positive value or becomes an object of negative value. This leads to the following proposition:

PROPOSITION 9.-Affective attachments to relations or groups will be stronger if those social units are perceived as stable and controllable sources of positive feelings from exchange; affective detachments (alienation) from relations or groups will be stronger if these social units are perceived as stable and uncontrollable sources of negative feelings.

\footnotetext{
${ }^{9}$ Negative feelings under the control of the other (intentional) would generate strong negative reactions to the other person, but not necessarily to the relation because intentionality is not applicable to social units, as it is to individuals. At the relational or group level, it is the lack of controllability and attendant hopelessness that is important.
} 
American Journal of Sociology

Relations, Networks, and Group Formation

There are two social units of prime importance to the affect theory: exchange relations and exchange networks. Relations are nested within networks, and networks are a set of connected dyadic ties (Emerson 1981). The theory shows how an exchange relation becomes a salient social unit and an object of affective attachment. If this occurs, the exchange relation takes on group properties (see Lawler and Yoon 1996). An important question is When might the network take on group properties? Emerson (1981) distinguished networks from groups but did not theorize the connection. This leads me to ask a second question: If the network is a social unit in the situation, will actors be attached more strongly to the subunit (relation) or to the larger unit (network)? The affect theory of social exchange can address these issues.

Network-to-group transformations.-With repeated exchange, one can imagine a network evolving into a group, thereby becoming a source of common identity for those in the network. Emerson distinguished two fundamental types of network: positively connected and negatively connected (Emerson 1972b, 1981; Molm and Cook 1995; Yamagishi, Gillmore, and Cook 1988). In positively connected networks, exchange by A and B increases the probability that they also exchange with others (C and D) who are available to them; that is, the network contains mutually supportive dyadic ties and incentives to interact with all those they are connected to in the network. In negatively connected networks, the probability of exchange between A and B is negatively related to the probability of exchange with others. These networks foster mutually exclusive dyadic ties. The incentives are to find the best and most profitable tie among those available. A comparison of positively and negatively connected networks has important implications for understanding when networks develop group properties.

Positively connected networks should promote the diffusion of emotions and feelings from one dyadic exchange relation to another. If actor $\mathrm{A}$ experiences positive feeling in exchanges with $\mathrm{B}$, then $\mathrm{A}$ should be more likely to establish exchange relations with $\mathrm{C}$, and experience similar positive feelings (Markovsky and Lawler 1994). This is suggested by a range of evidence indicating that persons in a positive emotional state (i.e., feeling good) are more cooperative and more inclusive in their dealings with others, even those who have no responsibility for the emotional state (e.g., see Isen [1987] for a review). The implication is that dyadic exchange in positively connected networks fosters affective attachments to the network and to relations within it. Negative emotions also spread but produce affective detachment from the network and its members. These effects can be explained by the fact that positively connected networks produce 
a stronger sense of a collective endeavor, because there is essentially a joint task at the network level that is activated by the spread of emotions and feelings across dyadic exchanges. Thus, the emotional effects of exchange within positively connected networks-whether the emotion is positive or negative-foster awareness of the network as a social unit and a propensity to perceive and act toward it as an object.

In negatively connected networks, positive emotions do not spread but instead become relation specific, as pockets of relational cohesion develop (Lawler and Yoon 1996). Dyadic relations are insulated from one another, and there is little basis for the network to be perceived as a unit unto itself or to develop grouplike properties. Negative emotions should generate a search for new partners or better deals and carry over from one exchange opportunity to another. Thus, negatively connected networks tend to fragment and break down into loosely connected or unstable patterns of dyadic exchange. Here are the main propositions based on this reasoning:

Proposition 10.-In positively connected networks, successful exchange in dyads strengthens affective attachments to the network as well as to particular exchange relations; whereas, in negatively connected networks, successful exchange in dyads strengthens affective attachments to exchange relations more than to the network.

Proposition 11.-In positively connected networks, repetitive exchange transforms the network into a group with dense ties; whereas, repetitive unsuccessful exchanges forestalls group formation and produces a network with sparse and loosely-connected ties.

Nested social units. - The nesting of relations in networks, assumed by network-exchange theories (Emerson 1981; Markovsky, Willer, and Patton 1988; Willer 1999), captures a fundamental feature of social life: People generally interact as members of subunits nested within larger units, e.g., subgroups in a group, divisions in a corporation, departments in a university, neighborhoods within a city. The affect theory can explain variation in the relative attachments to proximate social units or subunits (e.g., exchange relations) and larger social units (e.g., the network). To address this, ideas from two related theories are integrated, my own choice-process theory of affective attachments (Lawler 1992, 1997), and Collins's $(1975,1981,1989)$ theory of interaction ritual chains.

The main point of my (Lawler 1992, 1997) choice-process theory is that people form stronger affective attachments to those social units that give them the greatest sense of control (or self-efficacy). Having choices gives people a sense of efficacy that, in turn, produces positive emotions which are attributed to the social unit perceived as most responsible for their choice opportunity. The prediction is that people tend to give credit to the most immediate or proximal social unit for a sense of control or 
American Journal of Sociology

efficacy, but blame the more distant unit for the absence of choice and efficacy (Lawler 1992). Collins's (1981) theory of interaction ritual chains argues that people who repetitively interact develop common foci and common moods that symbolize their relationships or group memberships. His theory predicts greater solidarity from repetitive joint activities to the degree that the interaction engenders (1) common focus that actors recognize; (2) common feelings (uplift, confidence) that motivate action toward that common focus; (3) a sense of a "shared reality" manifest in the salience of common foci and the intensity of the emotional uplift. The result, according to the theory, is that actors come to "feel like members of a little group symbolized by whatever they focused on," and they feel a greater moral obligation to one another (Collins 1989, p.18).

Collins's theory places an emphasis on person-to-person interaction and argues that interpersonal "conversation" is the fountainhead of "emotional energy" that people take from one situation (conversation) to another. Emotional energy is a generalized motivational state involving feelings of warmth and confidence, not unlike the global feelings of pleasantness in the affect theory of social exchange or the "primitive emotions" of Weiner's (1986) theory. Repetitive interaction is the basis for solidarity at the micro level because of the feelings that actors associate with the common effort. Both Collins and I reach the same conclusion-namely that cohesion and solidarity is stronger in smaller face-to-face social units that constitute the immediate focus of attention. This implies a tendency (all other things equal) for exchange relations to be objects of stronger affective attachment than the social units (networks, groups) in which they are nested.

The rationale for this is that the local social unit-whether a relation in a network or a group in an organization-has an "interaction advantage." This is where joint tasks are undertaken and "definitions of the situation" crystallize (Lawler 1992, 1997). Because of this, positive emotions are attributed to the local unit, while negative emotions are attributed to the larger, more distant social unit. Applied to the four different exchange structures (fig. 2), one would expect exchange relations to be stronger objects of attachment in direct exchange structures (negotiated and reciprocal) than in productive or indirect structures. The interactional, person-to-person tie is more salient in direct exchange, whereas in productive and indirect exchange, the person-to-group tie is more salient (see also Lawler et al. 2000). In the former, positive emotions are attributed to relations within the network (relational attributions), and in the latter, they are attributed to the larger social unit (group attributions). This reasoning implies the following proposition:

PROPOSITION 12.-Structures of direct exchange produce relational attributions rather than group attributions for emotions, whereas structures 
Affect Theory

of productive or indirect exchange produce group rather than relational attributions.

Overall, the affect theory of exchange shows how emotional processes enhance or diminish the role of networks as a foundation for microsocial order. The theory argues that if networks are perceived by actors as a means for them to accomplish results that cannot be accomplished alone or in subunits, the conditions for group attributions to the network are present. The interweaving of self-efficacy with collective efficacy is fundamental. If, at the network level, there is a joint task that people come to see as such, then the processes articulated in propositions 1 and 2 should be activated, that is, nonseparability and perceptions of shared responsibility. If, at the network level, a particular form of exchange is occurring, then propositions 3-5 are applicable. Productive exchange at the network level would produce the strongest solidarity effects. Thus, the affect theory of social exchange offers testable implications for the conditions under which networks become real for actors, are objects of emotional attachment in their own right and a basis for person-to-group ties that buttress social order and solidarity.

\section{CONCLUSION}

The actors assumed by sociological exchange theory are unemotional, instrumental, information-processors, who respond to and anticipate future rewards and punishments. The affect theory of social exchange introduces an emoting actor, specifically, an actor who responds emotionally to exchange and who attempts to understand the source of their emotions and feelings. The theory draws particular attention to the joint activity entailed in social exchange and to the emotional responses to success or failure at that joint activity. A jointness-to-emotion process is the basis for explaining how and why different structures or forms of exchange generate varying degrees of order and solidarity. The theoretical argument contains five general claims, as follows:

The emotions produced by exchange are involuntary, internal responses. These emotions are felt as a "buzz" from accomplishing or not accomplishing an exchange task (i.e., as general feelings of pleasantness or unpleasantness). These feelings are a distinct class or type of reward (or punishment), and as such, actors are motivated to reproduce positive and avoid negative emotions in the future.

Actors engage in cognitive-interpretive work to understand what in the social situation produces their feelings. The affect theory of social exchange predicts that actors will attribute their exchange-based emotions to social units-relations, networks, groups-to the degree that the 
American Journal of Sociology

exchange brings them together around a common endeavor, renders their individual efforts or contributions indistinguishable (nonseparability), and creates a sense of shared responsibility for success or failure at exchange.

Exchange structures (negotiated, reciprocal, productive, generalized) determine the extent to which individual contributions to the task are nonseparable and the extent to which exchange fosters a sense of shared responsibility. In this context, the theory predicts that productive structures produce stronger social-unit attributions of emotion than negotiated or reciprocal structures, which, in turn, produce stronger social-unit attributions than generalized structures of exchange.

Exchange structures have an impact on relational or group solidarity through these emotional attributions and resulting affective attachments. Affective attachments to a social unit are formed especially when social units are perceived as stable and controllable causes of feelings such as pleasantness, pride, and gratitude; affective detachments occur when those social units are stable and uncontrollable causes of negative feelings (i.e., unpleasantness, shame, anger). In the theory, affective attachments are the proximal cause of behavior oriented toward the collective good, and affective detachments are the proximal cause of individually oriented behavior. Productive exchange produces the strongest affective attachments, generalized exchange the weakest, and negotiated and reciprocal exchange are in between.

Through the emotional/affective processes of the theory, networks can develop group properties. Specifically, a network, in which a given relation encourages relations to other available members of the network (positively connected network), tends to become a source of social similarity and common identity. A network that encourages cliques or pockets of denser relational ties (negatively connected network) tends to become a loosely connected set of subgroups, each promoting a stronger source of common identity than the larger unit. The affect theory predicts that, all things being equal, networks of negotiated and reciprocal exchange will tend to promote stronger relational ties within, whereas productive or generalized exchange will promote stronger network or group-level ties.

The affect theory of social exchange has broad implications for the role of emotions in the production of group solidarity (see also Collins 1981, 1989), because any social interaction entails a joint activity and an implicit, if not explicit, task. If the interaction is successfully accomplished and generates a positive result for actors, they are likely to feel good. This will motivate each to interact with the same others in the future, expecting another enjoyable result. With repetition, their relationship to each other or a larger group membership becomes salient as an object outside themselves (see also Berger and Luckmann 1966) and a target for the emotion experienced in interaction. A social network, by promoting repeated in- 
teractions among the same set of actors, could generate a group identity that binds together the actors in the network and distinguishes them from others. Thus, principles of the affect theory of social exchange can be extended to other forms of social interaction and, more generally, to social networks.

To conclude, social exchange has an instrumental foundation because people seek and form exchanges in order to receive individual benefits that they do not believe can be acquired elsewhere. My affect theory of exchange shows how the instrumental conditions of exchange foster expressive relations and groups through an emotional/affective process. In the theory, emotions are nonrational and outside the boundaries of rational choice in two respects: (1) emotions are involuntary, internal responses that simply "happen to people" (Hochschild 1979), and (2) emotions and the attribution processes they trigger transform relations, networks, or groups into expressive objects-that is, into a source of value. Emotional/ affective processes essentially move actors from the first (nonrational) point to the second (nonrational) point, but do so through a rational process; the actors' goal to reproduce pleasant feelings and avoid unpleasant ones motivates their linking of these nonrational states. In a larger sense, the affect theory of social exchange identifies some fundamental ways in which the rational and nonrational are intertwined in exchange processes and reveals implications for the solidarity of exchange relations and networks.

\section{REFERENCES}

Bandura, Albert. 1997. Social Learning Theory. Englewood Cliffs, N.J.: Prentice Hall. Berger, Peter L., and Thomas Luckmann. 1966. The Social Construction of Reality. New York: Doubleday.

Blau, Peter.M. 1964. Exchange and Power in Social Life. New York: Wiley.

Clore, Gerald L. 1994. "Why Emotions Require Cognition." Pp. 181-91 in The Nature of Emotion: Fundamental Questions, edited by P. Ekman and R. J. Davidson. New York: Oxford University Press.

$\rightarrow$ Clore, Gerald L., Andrew Ortony, and Mark A. Foss 1987. "The Psychological Foundations of the Affective Lexicon." Journal of Personality and Social Psychology 53:751-66.

Collins, Randall. 1975. Conflict Sociology. New York: Academic Press.

$\rightarrow-$ 1981. "On the Microfoundations of Macrosociology." American Journal of Sociology 86:984-1014.

$\rightarrow-$ 1989. "Toward a Neo-Meadian Sociology of Mind." Symbolic Interaction 12: $1-32$.

Cook, Karen S., and Richard M. Emerson. 1978. "Power, Equity, and Commitment in Exchange Networks." American Sociological Review 27:41-40.

. 1984. "Exchange Networks and the Analysis of Complex Organizations." Pp. 1-30 in Research on the Sociology of Organizations, vol. 3. Edited by S. B. Bacharach and E. J. Lawler. Greenwich, Conn.: JAI Press.

$\rightarrow$ Cook, Karen S., Richard M. Emerson, Mary R. Gillmore, and Toshio Yamagishi. 1983. 


\section{American Journal of Sociology}

"The Distribution of Power in Exchange Networks: Theory and Experimental Evidence." American Journal of Sociology 89:275-305.

$\rightarrow$ Cook, Karen S., and Joseph Whitmeyer. 1992. "Two Approaches to Social Structure: Exchange Theory and Network Analysis." Annual Review of Sociology 18:109-27.

Deci, Edward L. 1980. The Psychology of Self Determination. Lexington, Mass.: Lexington Books.

Duck, Steve. 1988. Relating to Others. Chicago: Dorsey Press.

Ekeh, P. P. 1974. Social Exchange Theory: The Two Traditions. Cambridge, Mass: Harvard University Press.

Emerson, Richard M. 1972a. "Exchange Theory, Part 1: A Psychological Basis for Social Exchange." Pp. 38-57 in Sociological Theories in Progress, vol. 2. Edited by J. Berger, M. Zelditch, Jr., and B. Anderson. Boston: Houghton-Mifflin.

1972b. "Exchange Theory Part 2: Exchange Rules and Networks." Pp. 58-87 in Sociological Theories in Progress, vol. 2. Edited by J. Berger, M. Zelditch, Jr., and B. Anderson. Boston: Houghton-Mifflin.

- 1981. "Social Exchange Theory." Pp. 30-65 in Social Psychology: Sociological Perspectives, edited by M. Rosenberg and R. H. Turner. New York: Basic Books.

Frank, Robert H. 1988. Passions within Reason: The Strategic Role of Emotions. New York: W.W. Norton.

$\rightarrow$ Friedkin, Noah E. 1992. "An Expected Value Model of Social Power: Predictions for Selected Exchange Networks." Social Networks 14:213-29.

Frijda, N. H. 1993. The Emotions. Cambridge: Cambridge University Press.

Gordon, Steven L. 1981. "The Sociology of Sentiments and Emotion." Pp. 562-92 in Social Psychology: Sociological Perspective, edited by Morris Rosenberg and Ralph H. Turner. New York: Academic Press.

Hechter, Michael. 1987. Principles of Group Solidarity. Berkeley and Los Angeles: University of California Press.

Heise, David R. 1979. Understanding Events. New York: Cambridge.

Hegtvedt, Karen A., and Barry Markovsky. 1995. Justice and Injustice. Pp. 257-80 in Sociological Perspectives on Social Psychology, edited by Karen Cook, Gary Alan Fine, and James S. House. Boston: Allyn \& Bacon.

Hewstone, Miles. 1989. Causal Atribution: From Cognitive Processes to Collective Beliefs. Oxford: Blackwell.

$\rightarrow$ Hochschild, Arlie R. 1979. "Emotion Work, Feeling Rules, and Social Structure." American Journal of Sociology 85 (3): 551-75.

. 1983. The Managed Heart: Commercialization of Human Feeling. Berkeley and Los Angeles: University of California Press.

Homans, George L. 1961. Social Behavior: Its Elementary Forms. New York: Harcourt Brace Jovanovich.

Isen, A. M. 1987. "Positive Affect, Cognitive Processes, and Social Behavior." Pp. 203-53 in Advances in Experimental Social Psychology. New York: Academic Press. Izard, Carroll E. 1991. The Psychology of Emotions. New York: Plenum Press.

Kelley, Harold H. 1967. "Attribution Theory in Social Psychology." Pp. 220-66 in Nebraska Symposium on Motivation, vol. 15. Edited by Donald Levine. Lincoln: University of Nebraska Press.

Kelley, Howard H., and John W. Thibaut. 1978. Interpersonal Relations: A Theory of Interdependence. New York: Wiley.

Kemper, Theodore D. 1978. A Social Interactional Theory of Emotions. New York: Wiley.

$\rightarrow$ - 1987. "How Many Emotions Are There? Wedding the Social and the Autonomic Components.” American Journal of Sociology 93:263-89.

$\rightarrow$ Kollock, Peter 1994. "The Emergence of Exchange Structures: An Experimental Study of Uncertainty, Commitment, and Trust." American Journal of Sociology 100:315-45.

Larsen, Randy J., and Edward Diener. 1992. "Promises and Problems with the 
Circumplex Model of Emotion." Pp. 25-59 in Emotion, edited by Margaret S. Clark. Newbury Park, Calif.: Sage.

$\rightarrow$ Lawler, Edward J. 1992. "Choice Processes and Affective Attachments to Nested Groups: A Theoretical Analysis.” American Sociological Review 57:327-39.

. 1997. "Affective Attachments to Nested Groups: The Role of Rational Choice Processes." Pp. 387-403 in Status, Network, and Structure, edited by J. Szmatka, J. Skvoretz, and J. Berger. Stanford, Calif.: Stanford University Press.

$\rightarrow$ Lawler, Edward J., and Jeongkoo Yoon. 1993. "Power and the Emergence of Commitment Behavior in Negotiated Exchange." American Sociological Review 58: 465-81.

$\rightarrow$ - 1996. "Commitment in Exchange Relations: Test of a Theory of Relational Cohesion." American Sociological Review 61:89-108.

$\rightarrow \longrightarrow$. 1998. "Network Structure and Emotion in Exchange Relations." American Sociological Review 63:871-94.

$\rightarrow$ Lawler, Edward J., and Shane R. Thye. 1999. "Bringing Emotions into Social Exchange Theory." Annual Review of Sociology 25:217-44.

$\rightarrow$ Lawler, Edward J., Shane Thye, and Jeongkoo Yoon. 2000. "Emotion and Group Cohesion in Productive Exchange." American Journal of Sociology 106:616-57.

$\rightarrow$ Lazarus, Richard S. 1984. "On the Primacy of Cognition." American Psychologist 39: 124-29.

$\rightarrow$ Lovaglia, Michael J., and Jeffrey Houser. 1996. "Emotional Reactions and Status in Groups." American Sociological Review 61:867-83.

$\rightarrow$ Macy, Michael W. 1993. "Backward Looking Social Control." American Sociological Review 58:819-36.

Markovsky, Barry, and Edward J. Lawler. 1994. "A New Theory of Group Solidarity." Pp. 113-37 in Advances in Group Processes, vol. 11. Edited by B. Markovsky, K. Heimer, J. O'Brien, and E. J. Lawler. Greenwich, Conn.: JAI Press.

$\rightarrow$ Markovsky, Barry, David Willer, and Travis Patton. 1988. "Power Relations in Exchange Networks." American Sociological Review 53:220-36.

$\rightarrow$ Markovsky, Barry, David Willer, John Skvoretz, Michael Lovaglia, and Jeffrey Erger. 1993. "The Seeds of Weak Power: An Extension of Network Exchange Theory." American Sociological Review 58:197-209.

Mead, George Herbert. 1934. Mind, Self, and Society. Chicago: University of Chicago Press.

Molm, Linda. 1987. "Extending Power Dependency Theory: Power Processes and Negative Outcomes." Pp. 178-98 in Advances in Group Processes, vol. 4. Edited by E. J. Lawler and B. Markovsky. Greenwich, Conn.: JAI Press.

$\rightarrow \longrightarrow$. 1991. "Affect and Social Exchange: Satisfaction in Power-Dependence Relations." American Sociological Review 56:475-93.

$\rightarrow \longrightarrow$. 1994. "Dependence and Risk: Transforming the Structure of Social Exchange." Social Psychology Quarterly 57:163-89. Press.

Molm, Linda, and Karen Cook. 1995. "Social Exchange and Exchange Networks." Pp. 209-235 in Sociological Perspectives on Social Psychology, edited by K. S. Cook, G. A. Fine, and J. S. House. Boston: Allyn \& Bacon.

$\rightarrow$ Molm, Linda, Gretchen Peterson, and Nobuyuki Takahashi. 1999. "Power in Negotiated and Reciprocal Exchange." American Sociological Review 64:876-90.

North, Douglass C. 1990. Institutions, Institutional Change, and Economic Performance. New York: Cambridge University Press.

Parsons, Talcott. 1951. The Social System. New York: Free Press.

$\rightarrow$ Ridgeway, Cecilia, and Cathryn Johnson. 1990. "What Is the Relationship between Socioemotional Behavior and Status in Task Groups?" American Journal of Sociology 95:1189-1212. 


\section{American Journal of Sociology}

$\rightarrow$ Russell, J. A., Anita Weiss, and G. A. Mendelsohn. 1989. "Affect Grid: A Single-Item Scale of Pleasure and Arousal." Journal of Personal and Sociology Psychology 57 (3): 493-502.

Scheff, Thomas J. 1990. Microsociology: Discourse, Emotion and Social Structure. Chicago: University of Chicago Press.

$\rightarrow$ Skvoretz, John, and David Willer. 1993. "Exclusion and Power in Exchange Networks: A Test of Four Theories of Power in Exchange Networks." American Sociological Review 58:801-18.

Tajfel, Henri, and John C. Turner. 1986. "The Social Identity Theory of Intergroup Behavior." Pp. 7-24 in Psychology of Intergroup Relations, edited by S. Worchel and W. G. Austin. Chicago: Nelson-Hall.

Thibaut, John W., and Harold H. Kelley. 1959. The Social Psychology of Groups. New York: Wiley

$\rightarrow$ Weiner, Bernard. 1985. "An Attributional Theory of Achievement Motivation and Emotion." Psychological Review 92:548-73.

1986. An Attributional Theory of Motivation and Emotion. New York: Springer-Verlag.

Willer, David, ed. 1999. Network Exchange Theory. Westport, Conn.: Praeger Publishers.

Willer, David, and Bo Anderson. 1981. Networks Exchange and Coercion: The Elementary Theory and Its Applications. New York: Elsevier.

$\rightarrow$ Willer, David, Michael J. Lovaglia, and Barry Markovsky. 1997. "Power and Influence: A Theoretical Bridge." Social Forces 76 (2): 571-603.

$\rightarrow$ Williamson, Oliver E. 1981. "The Economics of Organization: The Transaction Cost Approach." American Journal of Sociology 87:549-77.

1985. The Economic Institutions of Capitalism. New York: Free Press.

$\rightarrow$ Yamagishi, Toshio, Mary R. Gillmore, and Karen S. Cook. 1988. "Network Connections and the Distribution of Power in Exchange Networks." American Journal of Sociology 93:833-51. 